\title{
Y25 freight car bogie models properties analysis by means of computer simulations
}

\author{
Tomáš Lack ${ }^{1, *}$, Juraj Gerlici ${ }^{1}$ \\ ${ }^{1}$ University of Žilina, Faculty of Mechanical Engineering, Department of Transport and Handling \\ Machines, Univerzitná 8215/1, 01026 Žilina, Slovak Republic
}

\begin{abstract}
The article deals with the results of the simulation analysis of a railway wagon bogie model. We analysed four freight wagon bogie variants for its dynamics properties research. The bogie models correspond in general to the Y25 bogie concept. The models were created in SIMPACK software enhanced by the RAIL module. From the research results depicted in the graphs we found out, that the newly designed bogie variant gives the best results when compared to the other analysed versions. The newly designed model consists of a standard Y25 bogie frame with two Lenoire friction dampers. This bogie is equipped with longitudinal linkages on both sides. These linkages are completed with a radial torsion binding, torsion rod, between side bogie parts. The contact of railway wheels and rails generates active forces affecting the surface contact, affecting the size of the normal and tangential stress, wear surfaces of the wheel/rail, or directly the size of the derailment.
\end{abstract}

Keywords: chassis, Lenoir, damper, coupling, simulation

\section{Introduction}

Freight wagon transportation is a widespread global phenomenon, where it is necessary to transport large quantities of goods especially over long distances in an efficient, energysaving and environmentally friendly manner [1]. The impact of goods transportation on the environment is achieved through the interaction of the railway track and wagon arising from the contact of individual wheels of the chassis with the rail [2-4].

In contact of railway wheels and rails, there are acting forces which have with their effect on the contact area, on the size of the normal and tangential stress, wear surfaces of the wheel and rail or directly on the anti-derailment stability [5-7].

The size of the forces acting on the wheel-rail contact when crossing the arc on track has a significant impact on the wheelset position in the track. If the radial position of wheelset (wheelset axis is perpendicular to the axis of the track) is at the minimal, ideally zero angle of attack, the guiding forces with minimum distortion appear [8,9]. This has a positive impact on the value to the anti-derailment factor and on the occurrence and impact of tangential stresses in the transverse direction (y) in the wheel-rail contact [10].

The chassis construction of freight wagons has a significant impact on the size and forces of the wheel-rail contact [11-18]. One of the most common chassis for rail freight

\footnotetext{
* Corresponding author: tomas.lack@fstroj.uniza.sk

Reviewers: Milan Sága, Milan Vaško
} 
services in Europe is the Y25-type chassis. In practice, there are several variations of this basic concept. In order to compare the results of the simulation analysis of the freight bogie railway model we have done a comparison of several construction variants right at Y25type bogie. Various computational procedures can be used in the assessment tools [2].

\section{Bogies and track models definition}

Y25 basic type. Chassis Y25 (Fig. 1), in addition to other details, is characterised by wheelset guidance, where the suspension with primary progressive friction damper is part of the axle box situated always on one side of the suspension of each wheelset axle box [8-11]. The bogies in standard configuration by crossing the arc record certain sizes of guiding forces, and these imply technical consequences.

In order to reduce these values, the chassis manufacturers have changed some design parameters of guidance of Y25 bogie wheelset, respectively the bogies were modified [5].

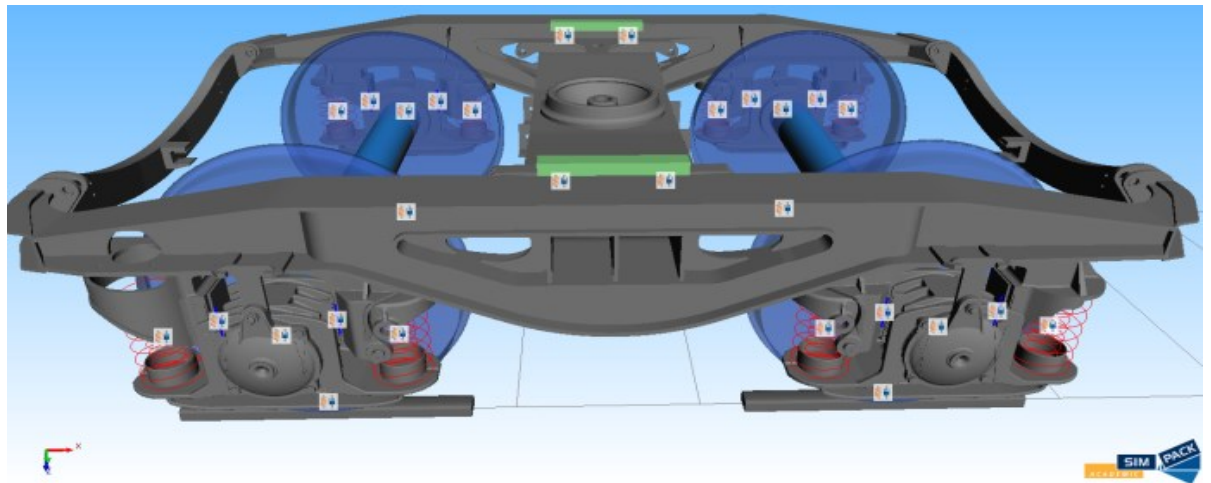

Fig. 1. Model of a standard Y25 bogie with a single Lenoir friction damper

Model of the Y25 bogie with two Lenoir dampers. One of the possible modifications is called "Release" of a wheelset in the longitudinal direction of the bogie with two Lenoir friction dampers (Fig. 2) and the connection of the front right wheel with the left rear wheel and also front left wheel with the rear right wheel using a cross coupling [5].

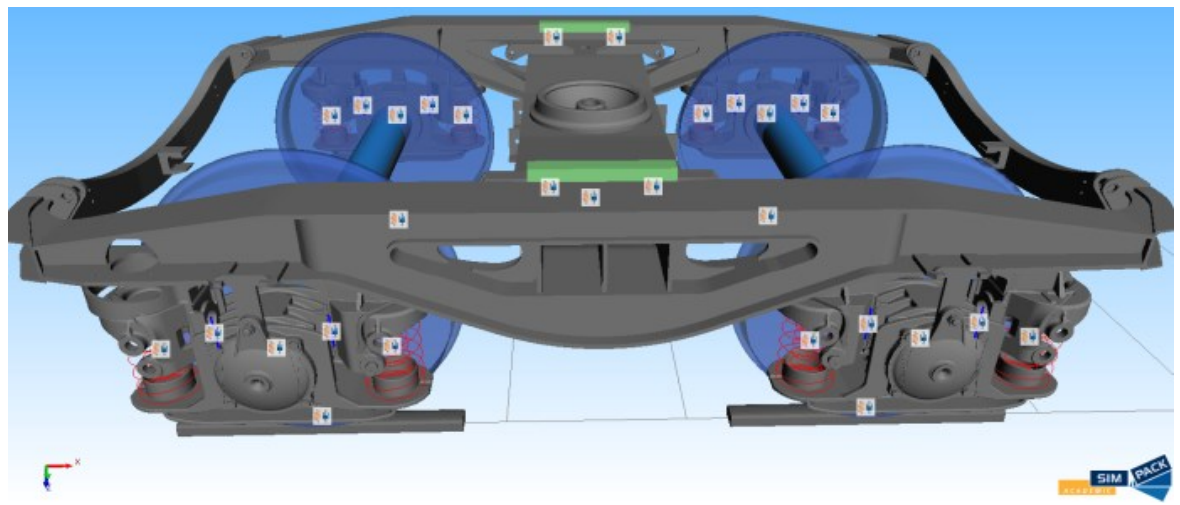

Fig. 2. Model of a Y25 bogie with two Lenoir friction damper

Model of the Y25 bogie with two Lenoir dampers. One of the possible modifications is the bogie model Z25 with two Lenoir dampers and a cross coupling (Fig. 3). 


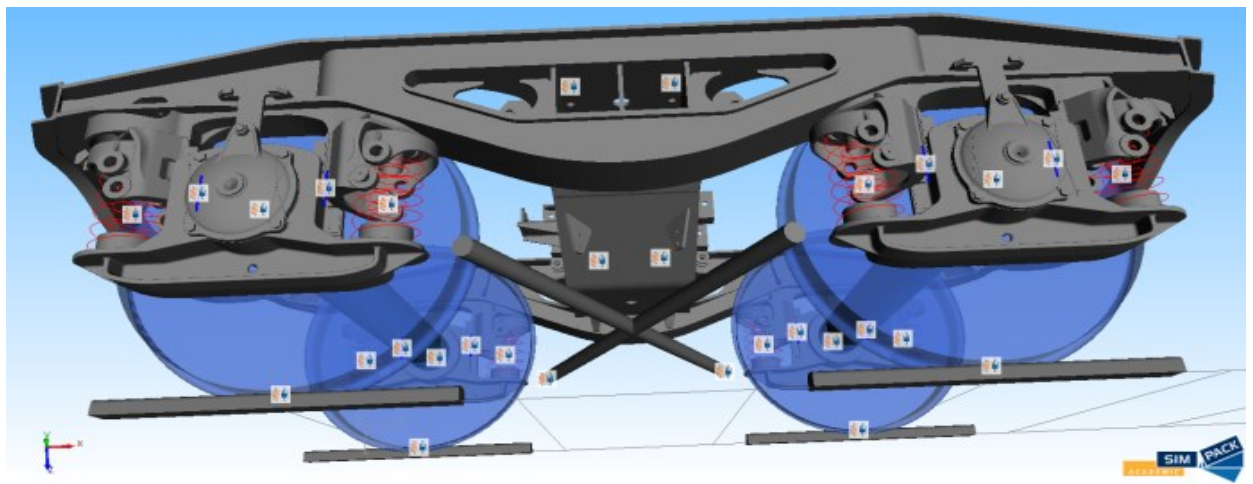

Fig. 3. Bogie Y25 linking wheelset cross-binding, view from below

Model of the Y25 bogie with two Lenoir dampers, longitudinal and transverse torsion. For modifications of a Y25 freight railway bogie we chose a modification inherent to railway vehicles of another category, designated for another purpose - the kind of vehicle, which has a bogie equipped with a longitudinal coupling between wheelsets, for illustration of real application.

The principle of application of longitudinal coupling extended by a transverse torsion coupling was implemented in the design of a new computational model of a freight bogie that can be investigated for the influence of some design changes, which we have applied to the expensive Y25 chassis (Fig. 4).

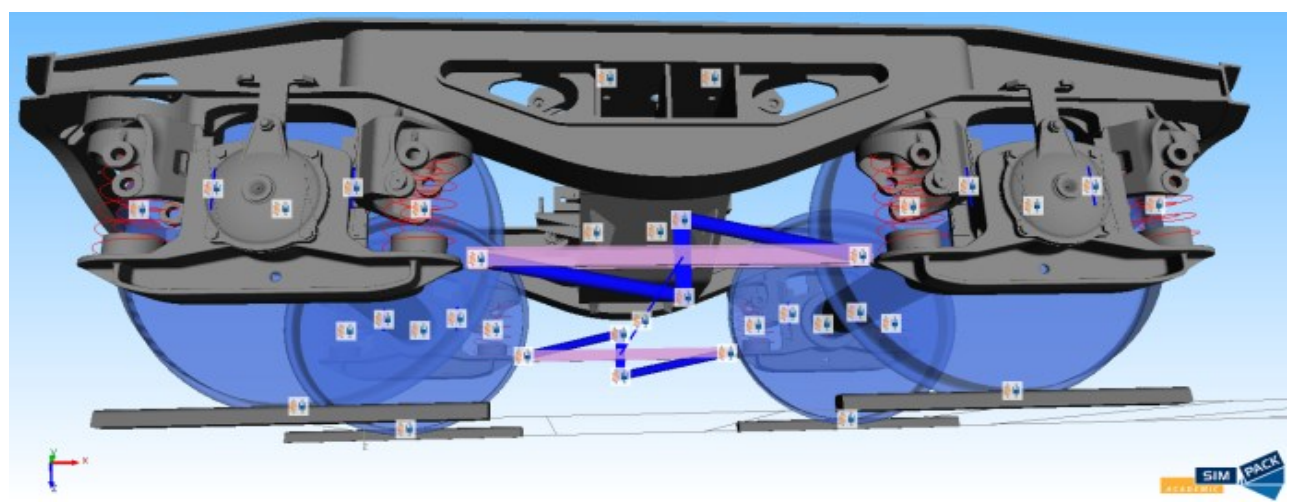

Fig. 4. Bogie Y25 with two Lenoir friction dampers linking wheelset with torsional binding - view from the bottom

Definiton of track simulation calculation. For simulations we have used standard definition of a model railway track of $1435 \mathrm{~mm}$, with a rail head profile UIC60. Railway wheels are equipped with driving profile S1002.

The decisive parameters for comparative calculations were only horizontal track geometry, which consisted of direct and four interlinked arches (Fig. 5, Fig. 6).

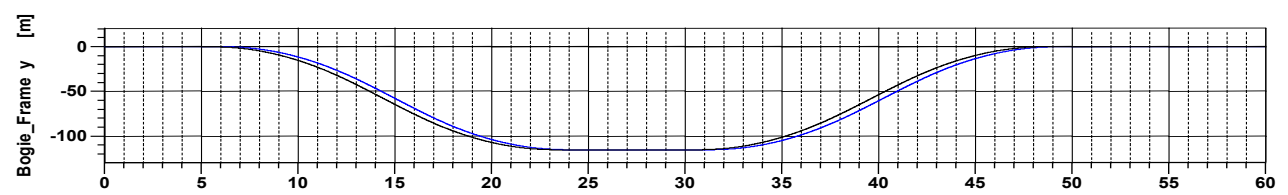

Fig. 5. Track geometry for simulation calculations - the CG of bogies 


\section{Comparison of the results of calculation}

The following section shows the results of calculations of all the four analyzed computational models. The evaluation focused on plotting the course of the guiding forces, angle of attack, wear number, the sum of guiding forces, safety against derailment, forces in drawbars in cross bonds, drawbar forces Fx in the longitudinal direction and the view of the rotation of torsional cross bond.

\subsection{Guiding forces}

Guiding forces at the first bogie are on the first wheelset and the leading wheel in the original design with a single Lenoir damper, Fig.1. In track arcs, the waveform values are the highest compared to other variants. Fig. 6-9 show this in a black line. In real practice we know solutions with cross-couplings, which diagonally connect opposite axle boxes of the bogie, as seen in Fig. 3. The results of the calculations in the graph are represented by the red curve.

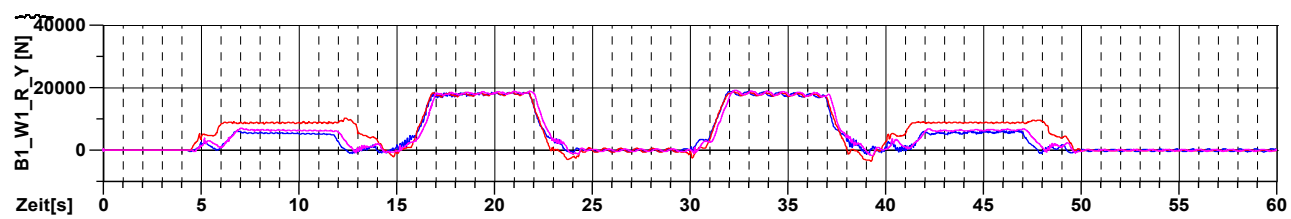

Fig. 6. Guiding force at the first bogie, the first wheelset, right wheel

In the simulation analysis, we created a model of variant without cross bond with released wheelsets with two Lenoir friction dampers which has the lowest guiding force, Fig. 2. In the graph it is shown as the blue line. This solution requires adding a stabilizing bonding of front and rear wheelset. Therefore, we have proposed an interconnection of the axle boxes by binding shown in Fig. 4. Guiding forces in this binding are shown in purple in the graph. This line closely copies variation of the forces without the cross bond. We can see that this interconnection is much more favorable than the currently used cross bond.

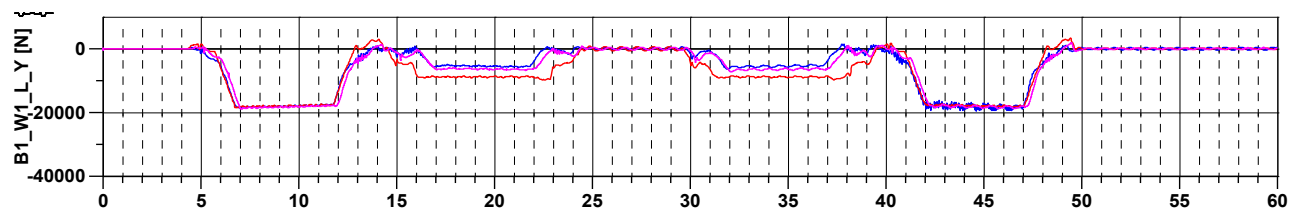

Fig. 7. Guiding force at the first bogie, the first wheelset, left wheel

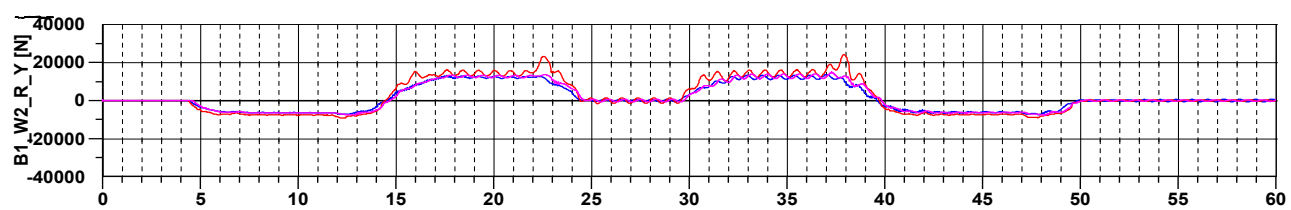

Fig. 8. Guiding force at the first bogie, the second wheelset, right wheel

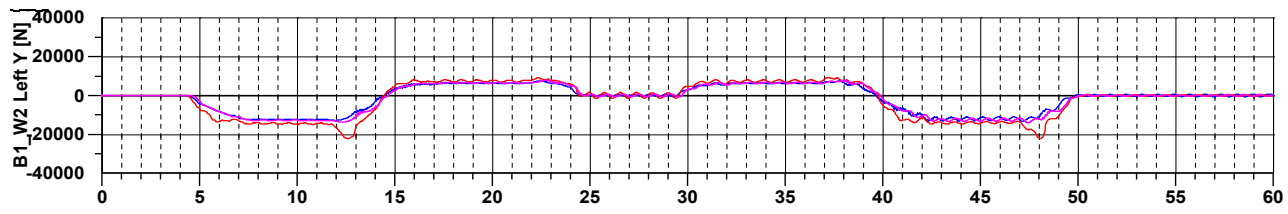

Fig. 9. Guiding force at the first bogie, the second wheelset, left wheel 


\subsection{Sum of guiding forces}

The summaries of the guiding forces (Fig. 10 - 11) acting on the individual wheelsets are very balanced and are primarily related to the operational characteristics of the vehicle, such as geometry, speed, vehicle weight. The new solutions of all variations have less than $20000 \mathrm{~N}$.

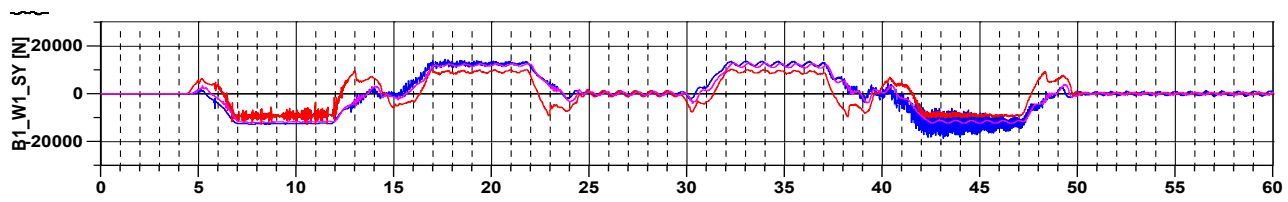

Fig. 10. Sum of guiding forces of the first wheelset first bogie

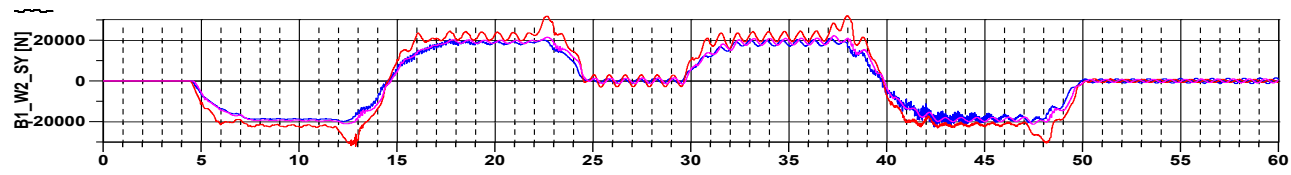

Fig. 11. Sum of guiding forces of the second wheelset first bogie

\subsection{Angle of attack}

When the bogie or wheelset passes the track arc, the angle of attack (Fig. 12 - 15) results from the position of the bogie or wheelset in the track when there is angular deviation of perpendicular to the axis of the wheelset (the bogie axis) and the axis of the track. In terms of evaluation of the angle of attack at the vehicle, it is the angle formed by the vehicle axis and the tangent to the arc of a track at the contact point of the loading wheel.

There are more wheelset technical solutions which should ensure passing of wheelset through the arc in the radial position to the track arc. These solutions have better or worse results.

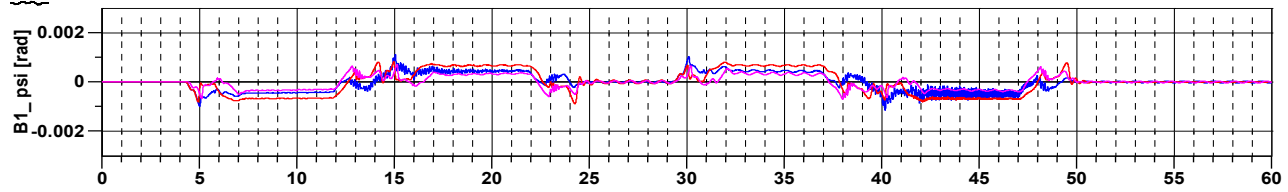

Fig. 12. Angle of attack of the first bogie

In any case, the wheelset position where the wheelset stands passing the arc of a track to a position approaching the radial position causes less guiding forces than in opposite case. This situation also affects the floating clearance in the longitudinal movement of the wheelset, which can be spent by setting the positioning.

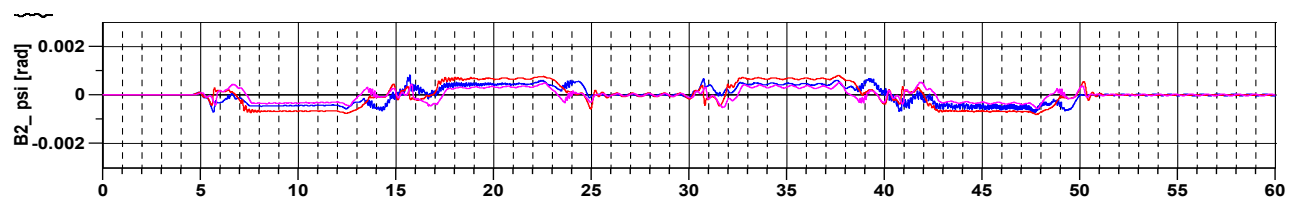

Fig. 13. Angle of attack of the second bogie 


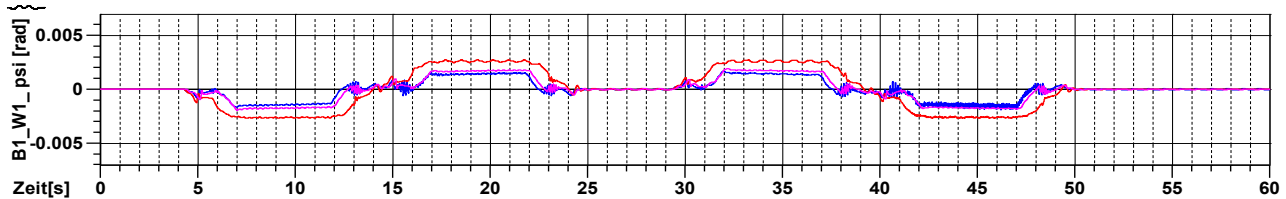

Fig. 14. Angle of attack of the first wheelset first bogie

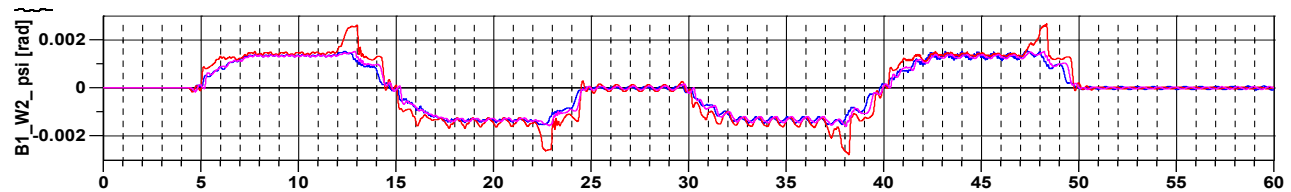

Fig. 15. Angle of attack of the second wheelset first bogie

Fig. $12-15$ clearly show that the solution of the bogie by releasing the wheelsets with two Lenoirs with the possibility of motion transfer by torsion coupling is a suitable solution in view of minimizing the angle of attack.

\subsection{Wear number}

The parameter of wear number in Fig. $16-17$ has a physical dimension of force $[\mathrm{N}]$. Wear number of contact area is calculated according to the formula (1):

$$
\left|T_{x} \cdot v_{x}\right|+\left|T_{y} \cdot v_{y}\right|+\left|M_{z} \cdot \varphi_{z}\right|
$$

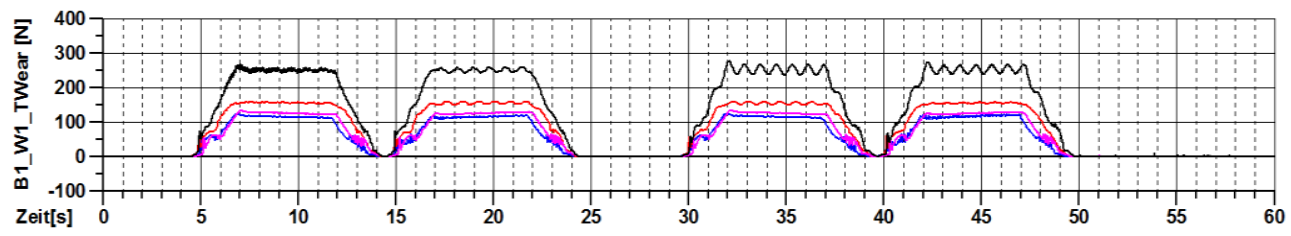

Fig. 16. Course of the wear number of the first wheelset first bogie

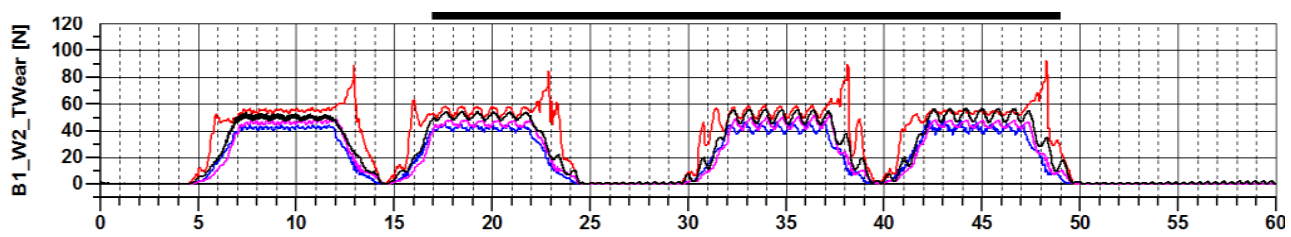

Fig. 17. Course of the wear number of the second wheelset first bogie

\subsection{Safety against derailment}

Expression of safety against derailment (Fig. 18 - 21) as a relative ratio equivalent to the proportion of the guiding forces and wheel forces on an individual wheels variations corresponds to its variation of the guiding forces. Higher values represents worse conditions, lower values represents a safer ratio of horizontal forces to the vertical for-ces. Although all values are significantly under the well-known lower accepted level of 0.8 , in this comparison we can see the extent to which one option is more preferable than the other, from this perspective. 


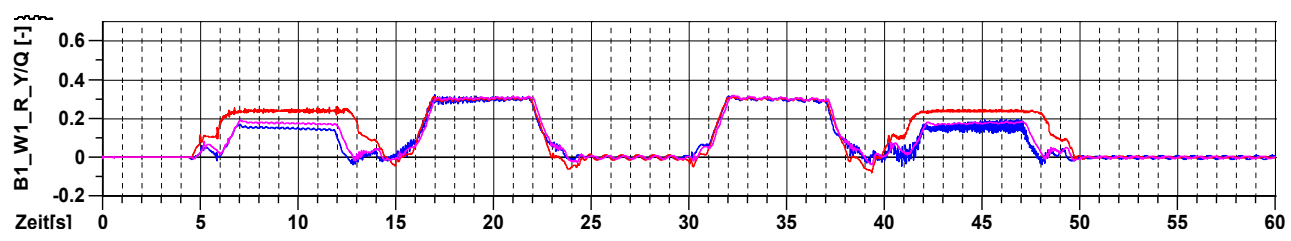

Fig. 18. Anti-derailment stability of the right wheel, first wheelset, first bogie

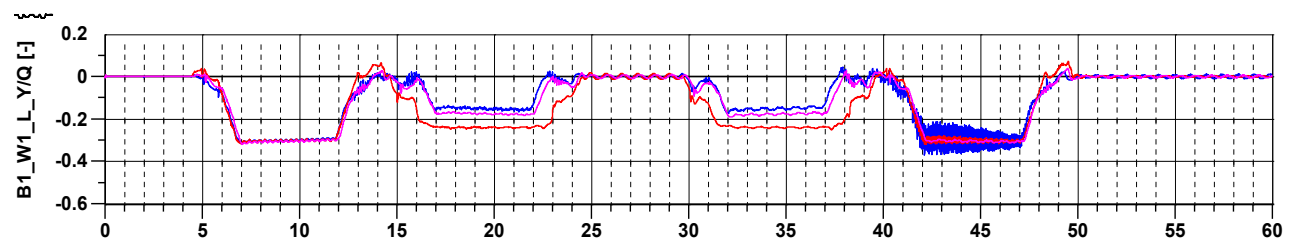

Fig. 19. Anti-derailment stability of the left wheel, first wheelset, first bogie

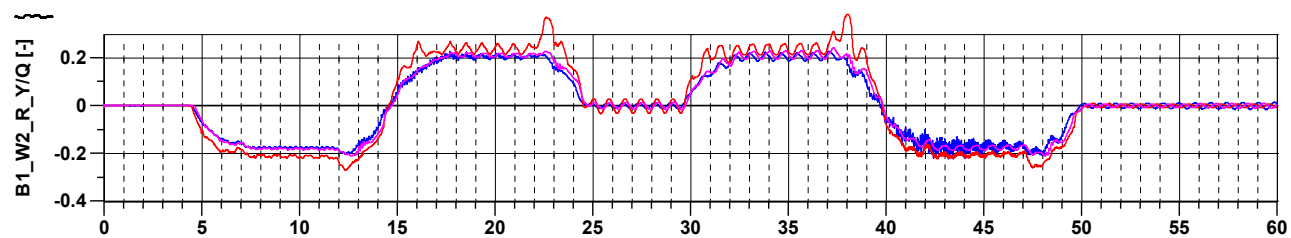

Fig. 20. Anti-derailment stability of the right wheel, second wheelset, first bogie

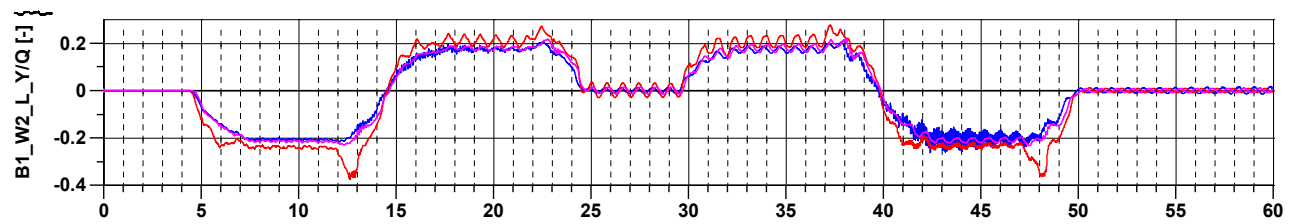

Fig. 21. Anti-derailment stability of the left wheel, second wheelset, first bogie

\subsection{Forces in drawbars of cross coupling}

Fig. 22 - 23 show the forces in drawbars of cross coupling, Fig. 3.

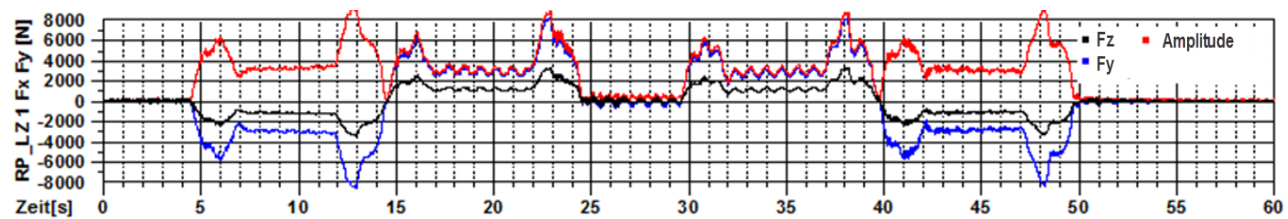

Fig. 22. First bogie, connect the right front axle box and the left rear

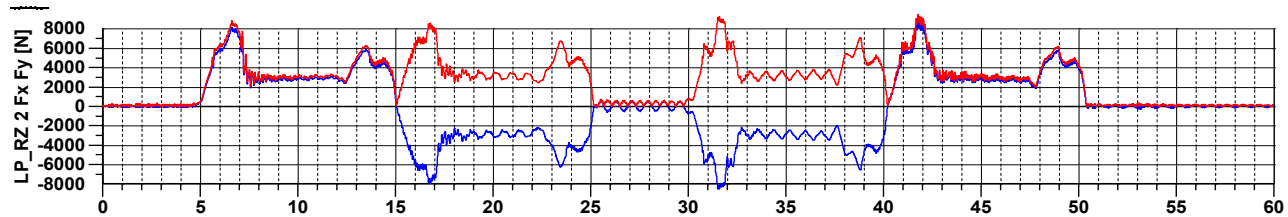

Fig. 23. First bogie, connect the left front axle box and the right rear 
In this case, the drawbars are transmitting the lateral forces. Fx curve shows the force in $\mathrm{x}$ direction, Fy curve shows the force in the $\mathrm{y}$ - direction and Amplitude shows the force in lonfitudinal drawbar direction.

\subsection{Fx forces in drawbars in longitudinal cross coupling}

Fig. $24-25$ show the forces in drawbars of cross coupling pulley of the transmission of longitudinal forces on the sides of the chassis in the variant of a newly designed cross coupling. In this case, the drawbars do not transmit lateral forces. The relative longitudinal displacements of the axle boxes are transferred to the other side of the chassis through a transverse torsion bond. The forces in these drawbars in the proposed longitudinal bond between the axle boxes are more than ten times smaller compared to the detected forces in the drawbars at cross-coupling in a classical variant bogie with cross coupling.

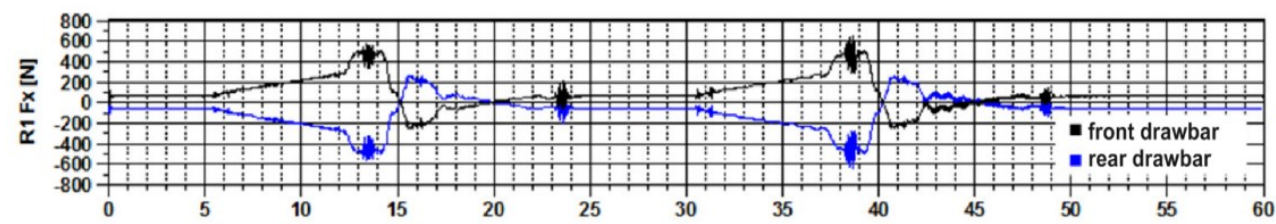

Fig. 24. Course of longitudinal forces Fx in drawbars on the right side of the first bogie

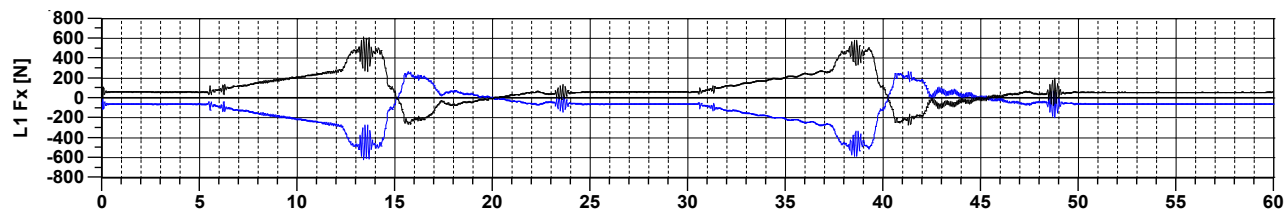

Fig. 25. Course of longitudinal forces Fx in drawbars on the left side of the first bogie

\subsection{Representation of course in rotation torsion bar of cross coupling}

Rotation of the torsion bar of cross bond of bogies represents a flexible rotational coupling at the sides of the bogie (Fig. 26, Fig. 27).

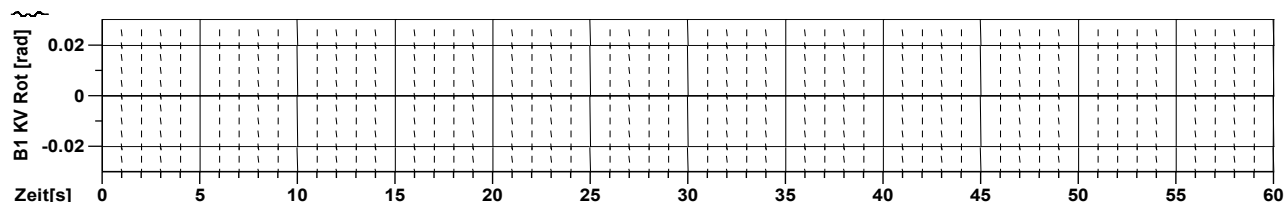

Fig. 26. Guiding force at the first bogie, the first wheelset, right wheel

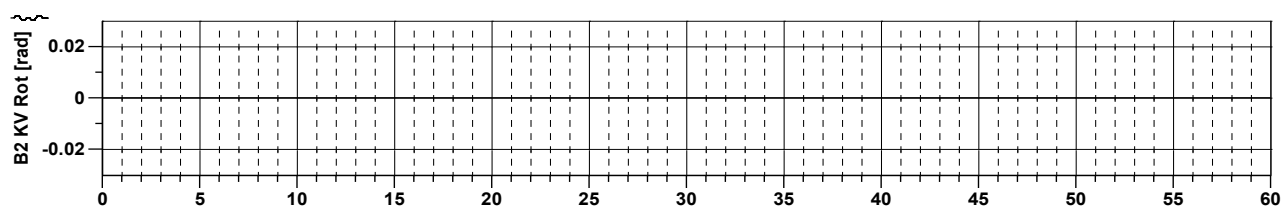

Fig. 27. Guiding force at the first bogie, the first wheelset, right wheel 


\section{Conclusions}

This article deals with the results of simulation analysis of a railroad freight bogie model to determine the dynamic properties of four variants of bogie construction, which corresponds to the type Y25. The models were created in SIMPACK software extended with RAIL module. All the bogie models have the same basic parameters similar to the Y25 (frame, wheelsets, connection to the chassis). The differences are only in the changed component.

Vehicles in the simulation software traverse the track with the same geometry. It's a model combination of straight track and four consecutive arcs. To achieve more significant differences in the results, the test track is only in the horizontal plane, which means the outer rail in arcs does not have any super-elevation installed. Vehicles go through the proposed model track at a constant speed.

The first variant is the basic model concept Y25 with one Lenoir friction damper in the primary suspension of the wheelset, the opposite side suspension is equipped only with springs and friction surface is rigidly clamped to the axle box. The second option is guiding with the released both sides of the wheelset axle box, each side of the wheelset is equipped with two flexible bonds with Lenoir friction dampers. The third option is guiding with the released both sides of the wheelset axle box, each side of the wheelset is equipped with two flexible bonds with Lenoir friction dampers. Wheelsets of each bogie are connected by direct cross-coupling. The fourth option is guiding with the released both sides of the wheelset axle box, each side of the wheelset is equipped with two flexible bonds with Lenoir friction dampers. Wheelsets of each bogie (front - rear) are connected with longitudinal coupling and also with torsion cross-coupling (left - right wheelset).

The result of simulation analysis are graphs of the examined parameters, guiding forces, anti-derailment safety, longitudinal force Fx in the drawbars on the sides of the bogies (in the fourth variant) and the wear numbers resulting from the action of force at a contact point. These graphs are completed with angle of attack information of bogies and wheelsets.

From the course of the examined values shown in the graphs we can see that the newly proposed variant of bogie type Y25 with released wheelsets, two Lenoir dampers, longitudinal coupling on the sides of the bogie complemented by transverse torsion coupling between the sides has a better dynamic behaviour of the vehicle in moving on the track, lower lateral guiding forces values, anti-derailment safety with using bogies with cross-coupling. Drawbars with longitudinal coupling feature smaller forces than drawbars with cross-coupling.

The work was supported by the Cultural and Educational Grant Agency of the Ministry of Education of the Slovak Republic in project No. KEGA 077ŽU-4/2017: Modernization of the Vehicles and engines study program. The work was also supported by the project No. APVV-0842-11: Equivalent railway operation load simulator on the roller rig and VEGA No. 1/0927/15: Research of the use of alternative fuels and hybrid drives on traction vehicles with aim to reduce fuel consumption and air pollutants production. Research-Educational Centre of Rail Vehicles (VVCKV)

\section{References}

1. J. Dižo, J. Harušinec, M. Blatnický, Multibody system of a rail vehicle bogie with a flexible body. Manufacturing Technology: Journal for Science, Research and Production 15, (5), 781-788 (2015)

2. M. Sága, R. Bednár, M. Vaško, Contribution to modal and spectral interval finite element analysis. Vibration Problems ICOVP 2011, Springer Proceedings in Physics, 139, 269-274 (2011) 
3. J. Dižo, Evaluation of ride comfort for passengers by means of computer simulation. In: Manufacturing Technology: Journal for Science, Research and Production 15 (1), 8-14 (2015)

4. J. Dižo, M. Blatnický, B. Skočilasová, Computational modelling of the rail vehicle multibody system including flexible bodies. Communications: scientific letters of the University of Žilina 17 (3), 31-36 (2015)

5. S. Iwnicki, Y. Bezin, A. Orlova, P. A. Johnsson, S. Stichel, H. Schelle, The 'SUSTRAIL' High Speed Freight Vehicle. Simulation of Novel Running Gear Design. Proc. of the 23rd Intern. Symposium on Dynamics of Vehicles on Roads and Tracks, 11. IAVSD. August 2013 Qingdao, China (2013)

6. T. Lack, J. Gerlici, Modified HHT method for vehicle vibration analysis in time domain utilisation. Applied mechanics and materials 486, 396-405 (2014)

7. A. Sapietová, M. Sága, P. Novák, R. Bednár, J. Dižo, Design and application of multisoftware platform for solving of mechanical multi-body system problems. Mechatronics: Recent technological and scientific advances, 345-354 (2011)

8. T. Lack, J. Gerlici, M. Maňurová, Analysis of dynamic properties of freight bogie model 1. In: Innovations in the concept, design, manufacturing and testing of freight II: January 2015, University of Zilina, 65-74 [In Slovak] (2014)

9. T. Lack, J. Gerlici, M. Maňurová, Analysis of dynamic properties of freight bogie model 2. In: Innovations in the concept, design, manufacturing and testing of freight II: January 2015, University of Zilina, 51-56 [In Slovak] (2015)

10. T. Lack, J. Gerlici, Freight car bogie analysis by means of simulation computations. In: PRORAIL 2015 Current problems in rail vehicles, 22nd intern. conference, Zilina, September 2015. ISBN 978-80-89276-48-6 [In Slovak] (2015)

11. T. Lack, J. Gerlici, Railway bogie properties analysis by means of simulation computations. Railway transport and logistics 11 (2), 54-60 [In Slovak] (2015)

12. M. Maňurová, A. Suchánek, Determination of stiffness of triple spring built in a bogie of a rail vehicle. In: Manufacturing Technology: Journal for science, research and production 16 (2), 390-396 (2016)

13. L. Jakubovičová, M. Sága, Computational analysis of contact stress distribution in the case of mutual stewing of roller bearing rings. Novel Trends in Production Devices and Systems, Applied Mechanics and Materials 474, 363-368 (2014)

14. P. Št’astniak, J. Gerlici, T. Lack, J. Harušinec, Computer aided simulation analysis for computation of modal analysis of the freight wagon. TRANSCOM 2013: $10^{\text {th }}$ European conference of young researchers and scientists: Žilina, June 24-26, 2013, Slovak Republic, Section 6: Machines and equipment, Applied mechanics, Žilina, University of Žilina, 297-300 (2013)

15. P. Pecháč, M. Sága, Controlling of local search methods' parameters in memetic algorithms using the principles of simulated annealing. Proc. Eng. 136, 70-76, (2016)

16. F. Nangolo, J. Soukup, J., The effect of asymmetry on vertical dynamic response of railway vehicles. Manufacturing Technology: Journal for science, research and production 14 (3), 375-380 (2014)

17. M. Svoboda, J. Soukup, Dynamic measurement of four-axle railway wagon. Manufacturing Technology 13 (4), 552-558 (2013)

18. J. Skočilas, B. Skočilasová, J. Soukup, Determination of the rheological properties of thin plate under transient vibration. Latin American Journal of Solids and Structures. Brasil society for mechanics and engineering, 1679-7825 [online] 